\title{
From fever to anti-malarial: the treatment-seeking process in rural Senegal
}

\author{
Lucy A Smith ${ }^{*}$, Jane Bruce ${ }^{1}$, Lamine Gueye ${ }^{2}$, Anthony Helou ${ }^{3}$, Rodio Diallo², Babacar Gueye ${ }^{2}$, Caroline Jones ${ }^{1}$, \\ Jayne Webster ${ }^{1}$
}

\begin{abstract}
Background: Currently less than 15\% of children under five with fever receive recommended artemisinincombination therapy (ACT), far short of the Roll Back Malaria target of $80 \%$. To understand why coverage remains low, it is necessary to examine the treatment pathway from a child getting fever to receiving appropriate treatment and to identify critical blockages. This paper presents the application of such a diagnostic approach to the coverage of prompt and effective treatment of children with fever in rural Senegal.
\end{abstract}

Methods: A two-stage cluster sample household survey was conducted in August 2008 in Tambacounda, Senegal, to investigate treatment behaviour for children under five with fever in the previous two weeks. The treatment pathway was divided in to five key steps; the proportion of all febrile children reaching each step was calculated. Results were stratified by sector of provider (public, community, and retail). Logistic regression was used to determine predictors of treatment seeking.

Results: Overall 61.6\% (188) of caretakers sought any advice or treatment and $40.3 \%$ (123) sought any treatment promptly within 48 hours. Over $70 \%$ of children taken to any provider with fever did not receive an anti-malarial. The proportion of febrile children receiving ACT within 48 hours was $6.2 \%$ (19) from any source; inclusion of correct dose and duration reduced this to $1.3 \%$. The proportion of febrile children receiving ACT within 48 hours (not including dose \& duration) was 3.0\% (9) from a public provider, 3.0\% (9) from a community source and $0.3 \%$ (1) from the retail sector. Inclusion of confirmed diagnosis within the public sector treatment pathway as per national policy increases the proportion of children receiving appropriate treatment with ACT in this sector from 9.4\% (9/96) to an estimated 20.0\% (9/45).

Conclusions: Process analysis of the treatment pathway for febrile children must be stratified by sector of treatment-seeking. In Tambacounda, Senegal, interventions are needed to increase prompt care-seeking for fever, improve uptake of rapid diagnostic tests at the public and community levels and increase correct treatment of parasite-positive patients with ACT. Limited impact will be achieved if interventions to improve prompt and effective treatment target only one step in the treatment pathway in any sector.

\section{Background}

Prompt and effective case management is a key component of global strategies to reduce the burden of malaria. The Roll Back Malaria Partnership (RBM) has set the target for 2010 that " $80 \%$ of malaria patients are diagnosed and treated with effective anti-malarial medicines, e.g. artemisinin-based combination therapies

\footnotetext{
* Correspondence: lucy.smith@lshtm.ac.uk

'Disease Control \& Vector Biology Unit, Department of Infectious \& Tropical Diseases, London School of Hygiene \& Tropical Medicine, Keppel Street, London. WC1E 7HT, UK

Full list of author information is available at the end of the article
}

(ACT), within one day of the onset of illness" [1]. Available data on progress towards this goal suggest that the mean proportion of children under five years of age with a fever that were treated with an anti-malarial drug in sub-Saharan Africa between 2007 and 2008 was 32\% (varying across countries from 6\% to 57\%); less than $15 \%$ of children were given an ACT (range: $3 \%$ to $25 \%$ ) [2]. These data do not include a measure of the promptness of treatment. Therefore, considering the delays in treatment-seeking reported elsewhere [3], it is likely that the proportion of children receiving an appropriate
C Biomed Central

C 2010 Smith et al; licensee BioMed Central Ltd. This is an Open Access article distributed under the terms of the Creative Commons Attribution License (<url>http://creativecommons.org/licenses/by/2.0</url>), which permits unrestricted use, distribution, and reproduction in any medium, provided the original work is properly cited. 
anti-malarial drug within one day of the onset of illness will be even lower.

Alongside the shift in national treatment polices to the use of more expensive forms of ACT, the policy process has recently changed to include parasitological diagnosis rather than presumptively treating all fevers as malaria [4]. This is particularly the case in the public sector $[5,6]$, however increasingly discussions are also moving towards introducing use of rapid diagnostic tests (RDTs) by community health workers $[7,8]$. Thus, it is important to consider diagnosis-confirmed cases of malaria, not just any febrile illness when assessing the proportion of malaria cases receiving prompt and effective treatment.

In order to understand why prompt and effective treatment of malaria (or fever) remains low it is necessary to examine the treatment pathway, comprising both treatment-seeking and the delivery process. Critical blockages in this treatment pathway may be identified by assessing the probability of a child moving from one step to the next, from getting a fever to receiving appropriate treatment [9]. Once critical blockages in the treatment pathway have been identified it may be possible to design new, or re-focus current interventions to move more rapidly towards the RBM target. If effective treatment of malaria is to be improved for children across socioeconomic groups, all sectors involved in the delivery of anti-malarials must be considered in this 'diagnostic' manner. Such an approach will enable the targeting of interventions to increase effective treatment at all sources that the caretakers of children are utilizing [10].

This paper presents the application of such a diagnostic approach to the coverage of prompt and effective treatment for febrile children in rural Senegal, assessing the critical steps at which children exit from the treatment pathway, stratified according to source of first advice or treatment.

\section{Methods}

\section{Study area and background}

Tambacounda is the largest region in Senegal, located in the south-east of the country and bordered by The Gambia, Guinea and Mali. The rainy season is from June to October and the majority of malaria transmission occurs between July and November [11]. Despite recent trends showing a decrease in the proportion of morbidity and mortality due to malaria in Senegal, there is still substantial regional variation. In the Tambacounda region malaria accounts for $13.5 \%$ of all outpatient consultations and $22.4 \%$ of mortality [12] and Tambacounda has the highest parasite prevalence in children under five of $23.4 \%$ compared to the national figure of 5.7\% [13].

The population of Tambacounda is widely dispersed and access to health care is often limited. The health system in Senegal is structured to have community outreach services at the village level through health huts (cases de santé), community health workers (agent de santé communautaire, ASC) and community health volunteers (relais communautaire, RC). However, in certain parts of the country these community level services are no longer functional. The international non-governmental organization IntraHealth is working to rehabilitate 24 health huts across Tambacounda, Koumpentoum and Maka Coulibantang districts. This rehabilitation was undertaken as part of an intervention to improve prompt and effective treatment of fever in children under five years with the national first-line anti-malarial, the ACT artesunate-amodiaquine (AS-AQ). The overall goals of the intervention are in alignment with the National Malaria Control Programme (Programme National de Lutte contre le Paludisme, PNLP) strategic plan to ensure correct treatment of $80 \%$ of malaria cases at all levels of the health system [14]. Each health hut serves its own village and four additional 'polarised villages' (villages polarisés). Prior to the final design and implementation of the intervention, a household survey of treatment practices for children under five years with fever was conducted between August $22^{\text {nd }}$ and September $2^{\text {nd }}$ 2008.

\section{Household survey design \& implementation}

The household survey followed a two-stage cluster sample design. The sampling frame for the survey covers all 110 villages that are served by the 24 intervention health huts in the districts of Tambacounda, Koumpentoum and Maka Coulibantang, which have an approximate total population of 37,770 . Each village represented a cluster and clusters were sampled proportional to population size.

To estimate the proportion of children under five years with fever in the last two weeks who received anti-malarial drugs within 24 hours with $6 \%$ precision and assuming a design effect of 2 , a non-response rate of $10 \%$, and the percentage of children under 5 years in the population as $17.5 \%$, a sample size of 240 was required [15]. To achieve this sample size, 40 clusters of 6 children under five years with fever in the last two weeks were sampled.

Households were selected within each cluster using an adapted form of the expanded programme of immunisation (EPI) cluster survey method [16]. A household was defined as all those eating from the same cooking pot [13]. Since the aim of this survey was to investigate the treatment practices for children under five years with fever, sampling of households was restricted to those with a child under five who had had fever in the past two weeks; no additional symptoms were specified in the inclusion criteria. Two selection questions were 
asked at each household: (i) Is there a woman present in this household with at least one child less than five years of age? (ii) Has this child (these children) had fever at any time in the last two weeks? Interviews were only continued with the child's caretaker where the answers to both of the selection questions were positive.

The survey tool included structured questions on respondent and household characteristics, details of the treatment process for children under five with fever (including source and timing of treatment, reported dose and duration of anti-malarials), and malaria-related knowledge.

\section{Data analysis}

Data were double-entered and validated in EpiData version 3.1 [17]. Stata 10.0 [18] was used for data processing and analysis. All analyses accounted for the design of the survey, adjusting for clusters. The survey design was self-weighting.

The treatment pathway was divided into five key steps and the proportion of children reaching each step calculated. The total number of febrile children was used as the denominator for all steps: (i) child had fever in the previous two weeks (denominator); (ii) child was taken for treatment or advice; (iii) care was sought within 48 hours; (iv) child received an anti-malarial; (v) child received an ACT. Prompt treatment is considered to be within 48 hours, defined as the day that the fever starts or the next day; the reason being that it is difficult to be sure on the precise number of hours and it is likely that 'the next day' will be more than 24 hours. The source of first advice or treatment was categorized to: community-based delivery point (defined as a health hut, ASC or RC); public health facility (defined as a health post or health centre; none of the caretakers reported first seeking care at a public hospital); or retail delivery point.

Traditional healers and friends/relatives were excluded from this categorization since we were interested in places where allopathic anti-malarial drugs could be given. Steps ii-v were calculated for treatment from any source, and from community, public and retail sector sources.

Principal components analysis (PCA) was used to assign each household a wealth index score based on household characteristics and ownership of assets [19]. The wealth index score was then used to classify households into three socioeconomic groups (tertiles). The variables included in the PCA were type of roof material, type of floor material, and household ownership of the following assets: solar panel, radio, television, telephone, mobile, fridge, bed, kettle, bucket, battery, sleeping mat, plough, horse, cow, goat, donkey, bicycle, motorbike, car, oxcart, horse and cart, donkey and cart. The proportion of variation explained by the first principle component was $17.7 \%$.
Univariable analyses of potential predictors of seeking any advice or treatment for a febrile child, and the source of first advice or treatment were explored using a logistic regression model; adjusted Wald tests were used to assess the contribution of each factor to the model. Potential predictors with a p-value of less than 0.1 were included in multivariable models for each of the outcome measures to ascertain which predictors remained associated with the outcome when adjusted for other factors.

\section{Modelling the impact of rapid diagnostic tests (RDTs)}

The survey was designed to assess access to prompt effective treatment and therefore used the Roll Back Malaria (RBM) access indicator as an outcome measure [20]. The Senegalese PNLP strategic plan states that all childhood fevers should be treated with AS-AQ within 24/48 hours of onset. However, at the time of the survey, communitybased diagnosis of malaria was based on symptoms alone (i.e. presumptive), whereas the policy stated that in public sector health facilities confirmatory diagnostic tests should be employed [14]. The RBM access indicator does not address the use of diagnostics in the treatment process and therefore no questions relating to diagnostics were included in the survey. As such, it was not possible to include empirical data on confirmed diagnosis in the algorithm for assessing appropriate treatment. To overcome this limitation we used routine data to model the impact of including RDT diagnosis in the treatment pathway assessments for the public sector.

For those seeking treatment from a public sector provider two additional steps were inserted into the treatment pathway. These steps were: the proportion receiving diagnosis with an RDT; and amongst those tested with an RDT, the proportion parasite positive. According to the most recent data from the PNLP, the proportion of patients with fever attending a formal public health facility in the Tambacounda region that received an RDT in 2008 was $78 \%$; the proportion of RDTs conducted that were positive for malaria in Tambacounda was $60 \%$ [12]. Thus, the denominator used for assessing appropriate treatment in the public sector where diagnosis should be RDT-confirmed was the expected number of children that would have confirmed malaria. This assumes that the decision not to administer an RDT to $22 \%$ of children with fever was based on sound clinical judgement of alternative diagnoses for these children rather than missed malaria cases.

\section{Ethical approval}

Ethical approval for the study was granted by the ethics committees of the Conseil National de Recherche en Santé (CNRS), Dakar, Senegal and London School of Hygiene \& Tropical Medicine, London, England. 


\section{Results}

Interviews were completed with 240 caretakers of children under five years of age with fever in the previous two weeks. As nearly a quarter of households had more than one child with a fever in the last two weeks a total of 305 febrile children were included in the survey sample. The mean number of febrile children under five years per household was 1.27 (range: 1 to 5 children). Since the majority of households with multiple febrile children under five years had two febrile children, potential clustering of treatment seeking outcomes was explored within these pairs of children. No agreement within child pairs for the outcome of receiving ACT within 48 hours was observed (correlation coefficient: $0.2344)$; therefore, the analysis was not adjusted for clustering at the household level. Household size varied from 3 to 39 people, with a mean of $11.0 \pm 5.2$. A total of 2,652 people lived in the households interviewed.

\section{Prompt treatment-seeking across sectors}

Overall 61.6\% (188) of caretakers sought any advice or treatment and $40.3 \%$ (123) sought any treatment promptly within 48 hours. Of the 188 children with fever for whom any advice or treatment was sought, the greatest number were taken to a health post (41.5\%), the lowest level public health facility; approximately equal numbers were taken to a health hut or community volunteer $(12.7 \%)$ or the retail sector $(13.8 \%)$; and $9.6 \%$ were taken to a public sector health centre. The remaining children were taken to an 'other' source (including $13.8 \%$ to a traditional healer, and $4.8 \%$ to a friend or relative or that already had drugs in the house).

The proportion of all children with fever that accessed the community or retail sectors was low $(7.8 \%$ and $8.5 \%$, respectively); however those who did, did so promptly with $83.3 \%$ and $80.8 \%$ accessing these delivery points within 48 hours, respectively. A lower proportion of the febrile children accessing public sector delivery points did so promptly $(63.2 \%)$. However, the difference in proportion promptly accessing the community $(\mathrm{p}=0.12)$ or retail $(\mathrm{p}=0.34)$ sector versus the proportion promptly accessing the public sector was not statistically significant. It is not unexpected that the community sector is the least accessed at the time of this survey as this was before the implementation of the health hut rehabilitation intervention.

\section{Predictors of seeking any advice or treatment}

Univariable logistic regression suggests that children of higher socioeconomic status are more likely to seek advice or treatment from any source, including traditional healers and friends or family, with those in the highest socioeconomic third twice as likely to seek any advice or treatment than those in the lowest third (lowest tertile: referent; middle tertile: OR: 1.86 ; $95 \% \mathrm{CI}$ : 0.98, 3.56; highest tertile: OR: 2.06; 95\%CI: 1.07, 3.98; $\mathrm{p}=$ 0.05 ) (see Table 1). No other predictors were significantly associated with seeking treatment from any source, thus it was not appropriate to construct a multivariable model.

\section{Predictors of where initial advice or treatment was sought}

Logistic regression was used to explore the predictors of seeking first advice or treatment at (i) a communitybased delivery point; (ii) a public health facility; and (iii) a retail sector delivery point. Traditional healers and family or friends were excluded from this categorisation $(n=42)$. The factors influencing treatment-seeking from the different categories of providers varied. For example, the univariable analyses (Table 2) suggested that the child's age and socioeconomic status were univariable predictors of first seeking care in the formal public health sector. The child's age and sex, and the number of wives of the head of household were predictors of first seeking care from a community-based source. Child's age and household size were univariable predictors of first seeking care for a child under five with fever from a retail outlet.

Not all variables remained associated when included in multivariable models (Table 3). For the public sector, child's age and socioeconomic status of the household remained predictors in the adjusted model. Older children (< 1 year olds: referent; 1 -4 year olds: OR: 0.53; $95 \%$ CI: $0.28,1.00 ; \mathrm{p}=0.05)$ and those of lower socioeconomic status (lowest tertile: referent; middle tertile: OR: 1.13; 95\%CI: 0.64, 1.99; highest tertile: OR: 2.14; 95\%CI: $1.17,3.91 ; \mathrm{p}=0.04$ ) were less likely to seek care from a public sector health facility when they have fever. The adjusted likelihood of a child with fever being taken to a community-based delivery point for first advice or treatment was greater for female children (OR: 3.53; 95\%CI: 1.47, 8.45; $\mathrm{p}=0.006$ ). The adjusted likelihood of a febrile child seeking first treatment from a retail outlet increased with household size $(<10 \mathrm{mem}-$ bers: referent; $10-14$ members: OR: 4.38 ; $95 \% \mathrm{CI}: 1.17$, 16.4; 15 or more members: OR: 4.69; 95\%CI: $1.03,21.3$; $\mathrm{p}=0.07)$

\section{Treatment received according to place first advice or treatment sought}

A greater proportion of children with fever in the previous two weeks received an anti-malarial, if they first sought treatment from a community-based delivery point $(62.5 \% ; \mathrm{n}=15)$. This was more than twice the proportion of those who received an anti-malarial if 
Table 1 Univariable logistic regression of the odds for seeking any advice or treatment for a child under five years with fever from any source

\begin{tabular}{|c|c|c|c|c|c|}
\hline Variable & $\mathbf{N}$ & $\%$ & OR & $95 \% \mathrm{Cl}$ & $\begin{array}{c}P \\
\text { value }\end{array}$ \\
\hline Child's age & & & & & 0.9 \\
\hline$<1$ year & 74 & 62.0 & 1.00 & & \\
\hline $1-4$ years & 234 & 61.5 & 0.98 & $0.56,1.73$ & \\
\hline Child's gender & & & & & 0.2 \\
\hline Male & 154 & 58.4 & 1.00 & & \\
\hline Female & 151 & 64.9 & 1.31 & $0.83,2.08$ & \\
\hline Mother's education & & & & & 0.1 \\
\hline None & 183 & 57.4 & 1.00 & & \\
\hline Any & 122 & 68.0 & 1.58 & $0.91,2.75$ & \\
\hline Mother's age & & & & & 0.3 \\
\hline$<20$ years & 56 & 71.4 & 1.00 & & \\
\hline 20-29 years & 120 & 64.2 & 0.72 & $0.31,1.66$ & \\
\hline $30-39$ years & 93 & 60.2 & 0.61 & $0.26,1.39$ & \\
\hline$>40$ years & 36 & 41.7 & 0.29 & $0.08,1.01$ & \\
\hline No. wives in $\mathrm{HH}$ & & & & & 0.1 \\
\hline One or less & 208 & 64.9 & 1.00 & & \\
\hline Two or more & 97 & 54.6 & 0.65 & $0.36,1.17$ & \\
\hline Household size & & & & & 0.9 \\
\hline$<10$ members & 112 & 61.6 & 1.00 & & \\
\hline 10-14 members & 129 & 62.8 & 1.05 & $0.54,2.05$ & \\
\hline 15 or more members & 64 & 59.4 & 0.91 & $0.45,1.86$ & \\
\hline No. U5s with fever in $\mathrm{HH}$ & & & & & 1.0 \\
\hline One & 183 & 61.7 & 1.00 & & \\
\hline Two or more & 122 & 61.5 & 0.99 & $0.51,1.91$ & \\
\hline Socioeconomic status* & & & & & 0.05 \\
\hline Lowest tertile & 98 & 50.0 & 1.00 & & \\
\hline Middle tertile & 106 & 65.1 & 1.86 & $0.98,3.56$ & \\
\hline Highest tertile & 95 & 67.4 & 2.06 & $1.07,3.98$ & \\
\hline $\begin{array}{l}\text { Seen malaria information in last } \\
\text { year }\end{array}$ & & & & & 0.7 \\
\hline No & 127 & 63.0 & 1.00 & & \\
\hline Yes & 178 & 60.7 & 0.91 & $0.56,1.47$ & \\
\hline
\end{tabular}

* 6 missing values for socioeconomic status

they first visited a public sector health post or health centre (29.5\% and $23.5 \%$, respectively) (Table 4$)$. Univariable logistic regression supports this finding with children first taken to a community-based service being approximately four times more likely to receive an antimalarial than those first taken to a public health facility (public sector health facility: referent; community-based delivery point: OR: 4.20 ; $95 \%$ CI: $1.49,11.80$; retail sector: OR: 0.46 ; 95\%CI: 0.11, 1.88; $\mathrm{p}=0.01$ ).

No antibiotics were given to children first seeking care from a health hut, which supports practice of the current national policy that antibiotics cannot be prescribed at the community level unless the community health workers are appropriately trained and supervised. The proportion of children seeking care in the public sector and receiving an antibiotic is higher (15.4\% and 35.3\% of those first seeking care at a health post or health centre, respectively).

Most of the 'other' treatments (i.e. neither an antimalarial nor an antibiotic) given to febrile children were paracetamol, regardless of the source of first treatment/ advice (community-level: 7/9; formal public health facility: 30/45; retail sector: 19/21). Approximately half of children (46/94) receiving an anti-malarial or antibiotic also received paracetamol. Overall, 1.6\% (5) children received both an anti-malarial and an antibiotic. Nine percent of the children taken to a health post as the first source of treatment or advice did not ultimately receive any treatment; this compares with $40 \%$ of those initially taken to a traditional healer. All children who were first taken to a health hut or health centre received some kind of treatment.

The proportion of febrile children taking an ACT within 48 hours was $6.2 \%$ (19) from any source, 3.0\% (9) from a formal public provider, $3.0 \%$ (9) from a community source and $0.3 \%$ (1) from the retail sector. Only $1.6 \%$ (5) also took the correct dose, and 1.3\% (4) for the correct duration forming the complete indicator for prompt and effective treatment, all of whom were children first taken to a community provider.

\section{Treatment process analysis}

By categorising the treatment process into key steps it is possible to visualise the proportion of children progressing through each step and to investigate at which step the greatest number of children exit the process required to receive effective treatment. This analysis can be further stratified by the sector or treatment delivery point of first seeking treatment (Figure 1). Overall, the greatest proportional loss occurs after treatment has been sought from any source; over $70 \%$ of children seeking treatment do not go on to receive an anti-malarial. Amongst those children that are given an anti-malarial just over half $(55.9 \%)$ receive an ACT.

Simple modelling of changes at various steps in the treatment process, based on the empirical data shown in Figure 1, suggests that increasing the proportion of children seeking care at community based treatment delivery points (health huts) would be a relatively effective way of increasing the proportion of febrile children receiving effective treatment. Increasing the proportion of children seeking treatment from a community delivery point (7.8\%) to the level of current treatment-seeking from the formal public sector (31.5\%) increases the proportion ultimately receiving treatment with an ACT from $2.9 \%$ to $11.8 \%$ (Table 5). Increasing the proportion of febrile children seeking treatment from a community delivery point to the current percentage seeking 
Table 2 Univariable logistic regression models of the odds for seeking any advice or treatment for a child under five years with fever from the public sector, community sector or retail sector

\begin{tabular}{|c|c|c|c|c|c|c|c|c|c|c|c|c|c|}
\hline \multirow[b]{2}{*}{ Variable } & \multirow[b]{2}{*}{$\mathrm{N}$} & \multicolumn{4}{|c|}{$\begin{array}{l}\text { First seek treatment in public } \\
\text { sector }\end{array}$} & \multicolumn{4}{|c|}{$\begin{array}{l}\text { First seek treatment in } \\
\text { community sector }\end{array}$} & \multicolumn{4}{|c|}{$\begin{array}{l}\text { First seek treatment in retail } \\
\text { sector }\end{array}$} \\
\hline & & $\%$ & OR & $95 \% \mathrm{Cl}$ & $P$ value & $\%$ & OR & $95 \% \mathrm{Cl}$ & $P$ value & $\%$ & OR & $95 \% \mathrm{Cl}$ & $P$ value \\
\hline Child's age & & & & & 0.05 & & & & 0.09 & & & & 0.06 \\
\hline$<1$ year & 74 & 42.3 & 1.00 & & & 2.8 & 1.00 & & & 1.4 & 1.00 & & \\
\hline $1-4$ years & 234 & 28.2 & 0.54 & $0.29,1.00$ & & 9.4 & 3.58 & $0.81,15.9$ & & 10.7 & 8.37 & $0.92,76.6$ & \\
\hline Child's gender & & & & & 0.2 & & & & 0.008 & & & & 0.2 \\
\hline Male & 154 & 27.9 & 1.00 & & & 3.9 & 1.00 & & & 11.0 & 1.00 & & \\
\hline Female & 151 & 35.1 & 1.40 & $0.83,2.34$ & & 11.9 & 3.34 & $1.40,7.97$ & & 6.0 & 0.51 & $0.16,1.61$ & \\
\hline Mother's education & & & & & 0.6 & & & & 0.4 & & & & 0.1 \\
\hline None & 183 & 32.8 & 1.00 & & & 6.6 & 1.00 & & & 6.0 & 1.00 & & \\
\hline Any & 122 & 29.5 & 0.86 & $0.45,1.63$ & & 9.8 & 1.55 & $0.56,4.33$ & & 12.3 & 2.19 & $0.79,6.06$ & \\
\hline Mother's age & & & & & 0.1 & & & & 0.6 & & & & 1.0 \\
\hline$<20$ years & 56 & 26.8 & 1.00 & & & 10.7 & 1.00 & & & 10.7 & 1.00 & & \\
\hline 20-29 years & 120 & 38.3 & 1.70 & $0.74,3.90$ & & 5.8 & 0.52 & $0.17,1.56$ & & 8.3 & 0.76 & $0.11,5.40$ & \\
\hline $30-39$ years & 93 & 31.2 & 1.24 & $0.47,3.23$ & & 8.6 & 0.78 & $0.28,2.21$ & & 7.5 & 0.68 & $0.10,4.42$ & \\
\hline$>40$ years & 36 & 16.7 & 0.55 & $0.11,2.81$ & & 8.3 & 0.76 & $0.11,5.14$ & & 8.3 & 0.76 & $0.11,5.21$ & \\
\hline No. wives in $\mathrm{HH}$ & & & & & 0.6 & & & & 0.05 & & & & 0.4 \\
\hline One or less & 208 & 30.3 & 1.00 & & & 9.1 & 1.00 & & & 9.6 & 1.00 & & \\
\hline Two or more & 97 & 34.0 & 1.19 & $0.65,2.17$ & & 5.2 & 0.54 & $0.29,1.00$ & & 6.2 & 0.62 & $0.21,1.86$ & \\
\hline Household size & & & & & 0.4 & & & & 0.1 & & & & 0.05 \\
\hline$<10$ & 112 & 36.6 & 1.00 & & & 12.5 & 1.00 & & & 2.7 & 1.00 & & \\
\hline $10-14$ & 129 & 31.0 & 0.78 & $0.38,1.61$ & & 7.0 & 0.53 & $0.23,1.22$ & & 11.6 & 4.78 & $1.29,17.7$ & \\
\hline$\geq 15$ & 64 & 23.4 & 0.53 & $0.21,1.31$ & & 1.6 & 0.11 & $0.01,0.96$ & & 12.5 & 5.19 & $1.14,23.6$ & \\
\hline No. U5s with fever in $\mathrm{HH}$ & & & & & 0.6 & & & & 0.2 & & & & 0.2 \\
\hline One & 183 & 32.8 & 1.00 & & & 9.8 & 1.00 & & & 6.6 & 1.00 & & \\
\hline Two or more & 122 & 29.5 & 0.86 & $0.47,1.56$ & & 4.9 & 0.47 & $0.16,1.38$ & & 11.5 & 1.85 & $0.65,5.24$ & \\
\hline Socioeconomic status* & & & & & 0.05 & & & & 0.6 & & & & 1.0 \\
\hline Lowest & 98 & 25.5 & 1.00 & & & 7.1 & 1.00 & & & 7.1 & 1.00 & & \\
\hline Middle & 106 & 28.3 & 1.15 & $0.65,2.04$ & & 6.6 & 0.92 & $0.23,3.68$ & & 6.6 & 0.92 & $0.33,2.55$ & \\
\hline Highest & 95 & 42.1 & 2.12 & $1.15,3.90$ & & 10.5 & 1.53 & $0.42,5.45$ & & 7.4 & 1.03 & $0.30,3.57$ & \\
\hline Seen malaria information in last year & & & & & 0.6 & & & & 0.1 & & & & 0.3 \\
\hline No & 127 & 33.1 & 1.00 & & & 4.7 & 1.00 & & & 11.0 & 1.00 & & \\
\hline Yes & 178 & 30.3 & 0.88 & $0.51,1.54$ & & 10.1 & 2.27 & $0.84,6.13$ & & 6.7 & 0.58 & $0.20,1.68$ & \\
\hline
\end{tabular}

* 6 missing values for socioeconomic status

Table 3 Multivariable logistic regression models of the odds for seeking any advice or treatment for a child under five years with fever from the public sector, community sector or retail sector (Note: multivariable regression not conducted for "any source" as only one variable met the inclusion criteria of a p-value $<0.1$ )

\begin{tabular}{|c|c|c|c|c|c|c|c|c|c|c|c|}
\hline \multicolumn{4}{|c|}{ First seek treatment in public sector } & \multicolumn{4}{|c|}{ First seek treatment in community sector } & \multicolumn{4}{|c|}{ First seek treatment in retail sector } \\
\hline Variable & OR & $95 \% \mathrm{Cl}$ & $P$ value & Variable & OR & $95 \% \mathrm{Cl}$ & $P$ value & Variable & OR & $95 \% \mathrm{Cl}$ & $P$ value \\
\hline Child's age & & & 0.05 & Child's age & & & 0.07 & Child's age & & & 0.08 \\
\hline$<1$ year & 1.00 & & & $<1$ year & 1.00 & & & $<1$ year & 1.00 & & \\
\hline $1-4$ years & 0.53 & $0.28,1.00$ & & 1-4 year & 3.53 & $0.90,17.7$ & & 1-4 years & 7.42 & $0.79,69.6$ & \\
\hline \multirow[t]{2}{*}{ Socioeconomic status* } & & & 0.04 & Gender & & & 0.006 & Household size & & & 0.07 \\
\hline & & & & Male & 1.00 & & & & & & \\
\hline Lowest & 1.00 & & & Female & 3.53 & $1.47,8.45$ & & $<10$ & 1.00 & & \\
\hline Middle & 1.13 & $0.64,1.99$ & & & & & & $10-14$ & 4.38 & $1.17,16.4$ & \\
\hline \multirow[t]{4}{*}{ Highest } & 2.14 & $1.17,3.91$ & & & & & & $\geq 15$ & 4.69 & $1.03,21.3$ & \\
\hline & & & & No. wives & & & 0.08 & & & & \\
\hline & & & & $\leq 1$ & 1.00 & & & & & & \\
\hline & & & & $\geq 2$ & 0.56 & $0.29,1.07$ & & & & & \\
\hline
\end{tabular}


Table 4 Treatment given to children under five years with fever, according to place where first advice/ treatment sought

\begin{tabular}{lccccccccc}
\hline $\begin{array}{l}\text { Place where } \\
\text { advice/treatment } \\
\text { FIRST sought }\end{array}$ & \multicolumn{1}{c}{ Treatment given } \\
\cline { 2 - 10 } & $\begin{array}{c}\text { Any anti- } \\
\text { malarial } \\
\text { (AM) }\end{array}$ & AS-AQ & $\begin{array}{c}\text { Antibiotic } \\
\text { (AB) }\end{array}$ & $\begin{array}{c}\text { Other } \\
\text { (not an AM or } \\
\text { AB) }\end{array}$ \\
\cline { 2 - 10 } & $\%$ & $\mathbf{n}$ & $\%$ & $\mathbf{n}$ & $\%$ & $\mathbf{n}$ & $\%$ & $\mathbf{n}$ \\
\hline Health hut/ASC/RC & 62.5 & 15 & 45.8 & 11 & 0 & 0 & 37.5 & 9 \\
\hline Health post & 29.5 & 23 & 19.2 & 15 & 15.4 & 12 & 48.7 & 38 \\
\hline Health centre & 23.5 & 4 & 5.9 & 1 & 35.3 & 6 & 41.2 & 7 \\
\hline Retail sector & 15.4 & 4 & 3.8 & 1 & 7.7 & 2 & 80.8 & 21 \\
\hline
\end{tabular}

treatment from any provider (61.6\%) increases treatment with an ACT to $23.1 \%$.

However, the improvements seen in the outcome of receiving prompt effective treatment with an $\mathrm{ACT}$ remain modest if increasing the proportion of children successfully completing the process focuses on just one step in the pathway. Indeed, even when every step in the process was increased by $20 \%$, the overall proportion of febrile children who received an ACT from any source was still only $25.2 \%$ (see Additional file 1 for full results of this modelling process).

\section{Modelling the inclusion of RDT-confirmed diagnosis}

Based on the PNLP data for 2008, we assume that $78 \%$ of febrile children taken to a formal public sector health provider were tested with an RDT, and $60 \%$ of these were positive for malaria parasites. Applying these data to the survey findings and assuming that the $22 \%$ that do not receive an RDT have strong alternative clinical diagnoses, the proportion of children appropriately receiving an anti-malarial promptly from the public sector would rise from $16.7 \%(16 / 96)$ to $35.6 \%(16 / 45)$ and the proportion appropriately receiving an ACT from the

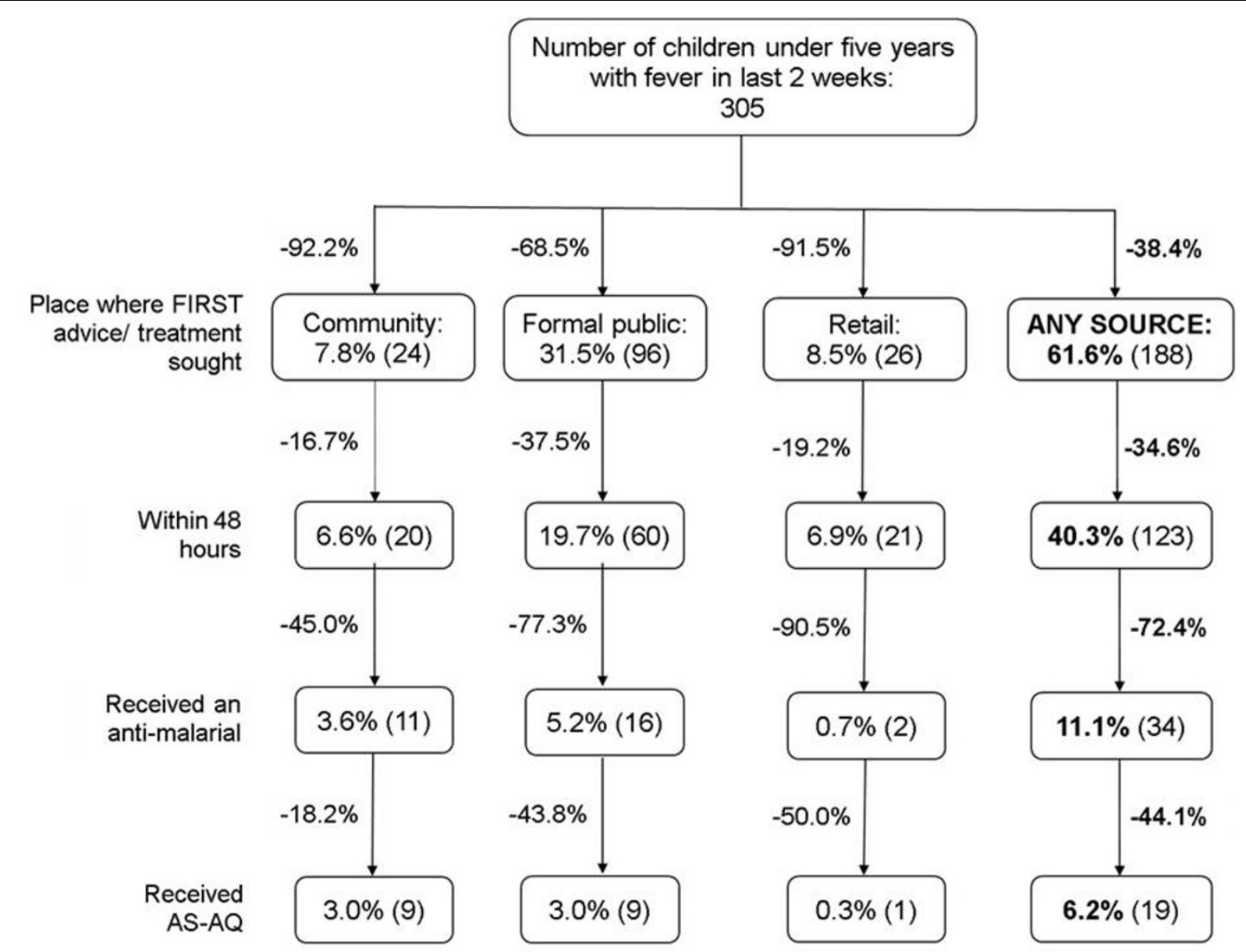

Figure 1 Treatment with an anti-malarial by source of first advice or treatment. Figures within boxes are proportions of all febrile children; percentages between boxes indicate the proportion of children that exit at each step in the pathway. 'Any source' indicates the total for each step, not stratified by provider. 
Table 5 Model to show how varying the proportion of febrile children passing through each step in the treatment pathway for those seeking care from a community delivery point influences the ultimate proportion that receive an ACT (unadjusted for RDT use)

\begin{tabular}{|c|c|c|c|c|c|c|c|c|c|}
\hline \multirow[b]{2}{*}{ Community delivery point } & \multicolumn{3}{|c|}{ Actual data } & \multicolumn{3}{|c|}{$\begin{array}{c}\text { Same proportion accessing as currently } \\
\text { go to public sector }\end{array}$} & \multicolumn{3}{|c|}{$\begin{array}{l}\text { Same proportion accessing as currently } \\
\text { go to any provider }\end{array}$} \\
\hline & $\mathbf{N}$ & $\%$ & Cum.\% & $\mathbf{N}$ & $\%$ & Cum.\% & $\mathbf{N}$ & $\%$ & Cum.\% \\
\hline 1. U5s with fever in last 2 weeks & 305 & 100 & 100 & 305 & 100 & 100 & 305 & 100 & 100 \\
\hline 2. Sought any advice or treatment & 24 & 7.8 & 7.8 & 96 & 31.5 & 31.5 & 188 & 61.6 & 61.6 \\
\hline 3. Within 48 hours & 20 & 83.3 & 6.5 & 80 & 83.3 & 26.2 & 157 & 83.3 & 51.3 \\
\hline 4. Received an AM & 11 & 55.0 & 3.6 & 44 & 55.0 & 14.4 & 86 & 55.0 & 28.2 \\
\hline 5. Received an ACT & 9 & 81.8 & 2.9 & 36 & 81.8 & 11.8 & 70 & 81.8 & 23.1 \\
\hline
\end{tabular}

public sector would rise from $9.4 \%$ (9/96) to $20.0 \%$ ( $9 /$ 45) when RDT confirmation was included. Because the role of diagnosis in the definition of "effective" treatment is different across sectors, it is not possible to construct an overall indicator for prompt and effective treatment of the original cohort of 305 febrile children if public sector RDTs are included since the denominator for the public sector then becomes different to that for the community and retail sectors.

\section{Discussion}

It is clear that large proportions of children exit from each step in the treatment pathway, and that a variety of interventions will be required to increase the proportion of febrile children with malaria receiving prompt and effective treatment with an ACT in the study area. Almost $40 \%$ of children with fever are not taken for any advice or treatment. This may be because the fever was only of short duration and the child quickly recovered, for example due to self-medication with drugs already in the home and/or other first aid measures such as tepid sponging. Nevertheless, the result still highlights the importance of health promotion to improve awareness of malaria symptoms and the importance of seeking prompt treatment if initial home measures such as tepid sponging do not work. The proportion of children not seeking any treatment seems high in relation to other studies [21,22]; however it is similar to findings from Uganda [23], which also reported approximately $40 \%$ of children not seeking any care for fever. More investigation is clearly needed to understand initial treatment practices in the home, the reasons for not seeking treatment outside the home, and to follow up on health outcomes including estimation of the proportion of fevers that are self-limiting.

Perhaps the starkest finding from this process analysis of the treatment pathway was that over $70 \%$ of febrile children taken to any provider did not receive an antimalarial. Given the national policy for confirmed diagnosis in formal public health facilities, it is not unexpected that a lower proportion of febrile children received an anti-malarial when taken to a public health facility rather than a community delivery point. However, assuming that $47 \%$ of fevers are malaria (78\% febrile children receive an RDT and of these $60 \%$ are positive), one would expect $47 \%$ of febrile children to receive an $\mathrm{ACT}$ in the public sector whilst our findings show that only $26.7 \%$ of those promptly seeking treatment in the public sector received any anti-malarial and $15.0 \%$ an ACT. The proportion of those promptly seeking treatment for a febrile child at any provider and not being given an appropriate anti-malarial (i.e. AS-AQ) is $84.6 \%$. The not uncommon occurrence of children being given anti-malarials other than ACT (including chloroquine) in the public sector is an indication that improvements are still necessary. The results of the present study support those of the 2008 Senegal Malaria Indicator Survey, which found that only $2.2 \%$ of children in the Tambacounda region with fever in the previous two weeks received an ACT on the same or next day [24].

Effective treatment of malaria does not stop at prescription of an ACT to patients with a confirmed diagnosis; the caretaker of the child also needs to access the prescribed medication and fully adhere to the complete treatment regimen making sure that the child takes the correct dose and for the correct number of days. In addition to including an indication of promptness of treatment-seeking (within 48 hours of the child first showing signs of fever), these elements make up the full RBM indicator of prompt and effective treatment of malaria [1]. In this study, only $1.3 \%$ of children with fever received an ACT within 48 hours of presenting with fever, which was reportedly taken at the correct dose and for the correct duration.

The exiting of children from steps in the treatment pathway seen in this study is very similar to findings from Uganda; Nsungwa-Sabiiti et al found that in a population of 260 children with fever, $87 \%$ received any treatment, $44 \%$ within 24 hours, $26 \%$ with an appropriate anti-malarial and only $7 \%$ at correct dose and duration [25]. This emphasizes the need to target both users 
and providers if improvements in the prompt and effective treatment of malaria in children are to be achieved. Qualitative work is now needed to understand the reasons for the observed losses at each step in the treatment pathway in order to design appropriate interventions.

Studies investigating how the use of RDTs in routine health services influence clinical decisions have shown mixed results. For example, research in Tanzania and Burkina Faso found that many health providers continue to prescribe anti-malarials to patients with a negative RDT result [26,27], whereas this practice was much less frequent in studies in Kenya and Zanzibar [28,29]. Modelling of the impact of RDT-confirmed diagnosis did not incorporate interpretation of the result into the treatment received by the febrile child, meaning that some of those given an anti-malarial may have been negative and some of those not given an anti-malarial may have been positive which would have influenced the proportion of febrile children being appropriately treated. RDTs are likely to be less cost effective if the results are not used properly, particularly in areas with falling malaria transmission such as Senegal [12] and where treatment is with more expensive ACTs [30,31]. A key intervention in addition to increasing the use of RDTs in the public sector is, therefore, to encourage appropriate treatment of positive results with an anti-malarial (more importantly, an ACT) and negative results with a suitable alternative treatment, for example an antibiotic or antipyretic.

Interestingly, the proportion of febrile children taken to a health centre that were given an antibiotic supports that differential diagnosis based on a confirmed RDT may have been appropriately implemented since almost $40 \%$ of children received an antibiotic (approximately the proportion that would have been expected to receive a negative RDT). Overall, $1.6 \%$ of children received both an anti-malarial and an antibiotic. However, at the health post level only $15 \%$ of febrile children received an antibiotic. It is possible that the prescription of ACT was low in the public sector due to problems with stock-outs, known to have adverse effects on appropriate treatment of malaria in other countries after changing their national malaria drug policy [32]. Alternatively, it may have been because of health worker reluctance to prescribe AS-AQ due to perceived or observed side effects of amodiaquine which have previously been found in Senegal [33]. Household surveys are currently the standard method used to assess the RBM malaria treatment indicator; however, to truly understand the provider-side factors such as stock and quality of care that influence the ultimate treatment received and adhered to by children with malaria, it is necessary to also conduct concurrent health facility and health worker surveys.
In addition to the existing use of RDTs in public health facilities, they are also presently being rolled out for use in the diagnosis and treatment of malaria at the community level in Senegal. Community health workers (ASCs) will be supplied with RDTs and trained in their use. Use of RDTs by community volunteers has been shown to be feasible in other settings $[7,8]$; however, concerns with appropriate use of the tests and correct interpretation of results mean that close monitoring of the new system will be important. Similarly, the inclusion of a confirmed malaria diagnosis as a specific step in the treatment pathway, regardless of source of treatment, will be important in assessing effective treatment of febrile children in the intervention area in future surveys.

Another interesting, if not surprising, finding of this study is that there is minimal activity in the retail sector in relation to ACT; although $8.5 \%$ of febrile children were taken to a retail outlet, only $3.8 \%$ of these received an ACT.

The predictors for a child with fever seeking treatment vary depending on the type of provider that they are initially taken to. For example, access to the public sector increases with higher socioeconomic status. However, socioeconomic status is not a predictor of accessing community-based delivery points. This supports data from other studies that suggest providing ACT through community-based systems such as health huts may be an appropriate way to increase equity of access to effective malaria treatment [34]. However, there is still debate as to whether community health workers are able to increase socioeconomic equity in the coverage of interventions as effectively as they improve geographic equity, especially as some level of payment is usually involved $[35,36]$. Finding that carers of febrile children were seeking treatment from the community sector in areas with non-functional health huts may have been due to a small number of health huts being rehabilitated and receiving their ACT supplies whilst the survey was underway, or to people travelling large distances to access functioning health huts.

The sample size is a limitation of this survey, resulting in wide $95 \%$ confidence intervals. This is due to the decreasing numbers of children progressing to each step of the treatment pathway, particularly when they are stratified by provider and categorized determinant. Future studies wishing to assess the different steps in the treatment pathway, particularly when including stratification by type of provider, should allow a sufficiently large sample size to account for the decreasing numbers of children remaining in the evaluable sample as the pathway progresses.

It is important to note that there may be some inaccuracies in the names and types of drugs that the 
caretakers reported giving to their children [37], particularly due to problems with recall of an event that occurred up to two weeks ago. Although we tried to limit this source of bias by providing the interviewers with a photo board for anti-malarials available in the region, non anti-malarials were not included. It is difficult to predict however, whether this would mean antimalarials or non anti-malarials would have a greater chance of being reported by caretakers.

Despite the sample size and other limitations, it is clear that large proportions of children exit from each step in the treatment pathway, and that intervention is required at multiple steps to increase the proportion of febrile children with malaria receiving prompt and effective treatment in the study area.

\section{Conclusion}

Progress towards achieving the RBM goal of $80 \%$ of malaria patients being diagnosed and treated with effective anti-malarial medicines (ACT) within one day of the onset of illness is slow. In order to understand the reasons for this and to generate improvements, it is necessary to identify the steps within the treatment pathway where the greatest proportion of children exit from the process of receiving effective treatment. This will enable the identification of the steps where interventions can or should be targeted to achieve the greatest impact. Limited impact will be achieved if interventions only target one step in the pathway. In the Tambacounda region of Senegal, the most important targets for interventions are increasing initial care seeking for fever, improving uptake of RDTs at the public and community levels and correctly treating parasite positive patients with an ACT. There is also a need for complementary qualitative work to investigate in more detail why these processes are not occurring effectively so that the most appropriate interventions can be designed. It is important that this diagnosis of the treatment pathway is further broken down by provider type since the public, community-based and retail sectors behave differently but are all important if the RBM targets for prompt and effective treatment of malaria are to be achieved.

\section{Additional material}

Additional file 1: Model to show how varying the proportion of febrile children passing through each step in the treatment pathway (from any provider) influences the ultimate proportion that receives an ACT (unadjusted for RDT use).

\section{Abbreviations}

ACT: artemisinin combination therapy; AS-AQ: artesunate-amodiaquine; ASC: agent de santé communautaire [community health worker]; $\mathrm{Cl}$ : confidence interval; EPI: Expanded Programme on Immunisation; OR: odds ratio; PNLP:
Programme National de Lutte Contre le Paludisme [National Malaria Control Programme]; RC: relais communautaire [community health volunteer]

\section{Acknowledgements}

Many thanks to Pfizer's Mobilize Against Malaria initiative for providing the funding to support this research. The findings, views and opinions expressed in this article are those of the authors and not of Pfizer Inc.

\section{Author details}

${ }^{1}$ Disease Control \& Vector Biology Unit, Department of Infectious \& Tropical Diseases, London School of Hygiene \& Tropical Medicine, Keppel Street, London. WC1E 7HT, UK. ${ }^{2}$ IntraHealth International, Lot C \& E, Sacré-Coeur Pyrotechnie, Dakar, Senegal. ${ }^{3}$ Pfizer Canada Inc., Montreal, Canada.

\section{Authors' contributions}

$L S, J B, J W$, and $C J$ devised the study design and objectives. $L G, A H, L S, J W$, $J B, C J, B G$ and RD contributed to data collection, analysis and interpretation. LS did the analysis and wrote the first draft of the manuscript. All authors read, commented on and approved the final manuscript.

\section{Competing interests}

The authors declare that they have no competing interests.

Received: 22 July 2010 Accepted: 22 November 2010

Published: 22 November 2010

\section{References}

1. RBM: Global strategic plan: Roll back malaria 2005-2015 Geneva: Roll Back Malaria Partnership; 2005

2. WHO: World Malaria Report 2009 Geneva: World Health Organization; 2009

3. McCombie SC: Treatment seeking for malaria: a review of recent research. Soc Sci Med 1996, 43:933-945.

4. WHO: Guidelines for the treatment of malaria. 2 edition. Geneva: World Health Organization; 2010.

5. Drakeley $\mathrm{C}$, Reyburn $\mathrm{H}$ : Out with the old, in with the new: the utility of rapid diagnostic tests for malaria diagnosis in Africa. Trans $R$ Soc Trop Med Hyg 2009, 103:333-337.

6. Perkins MD, Bell DR: Working without a blindfold: the critical role of diagnostics in malaria control. Malar J 2008, 7(Suppl 1):S5.

7. Harvey SA, Jennings L, Chinyama M, Masaninga F, Mulholland K, Bell DR Improving community health worker use of malaria rapid diagnostic tests in Zambia: package instructions, job aid and job aid-plus-training Malar J 2008, 7:160.

8. Elmardi KA, Malik EM, Abdelgadir T, Ali SH, Elsyed AH, Mudather MA Elhassan AH, Adam I: Feasibility and acceptability of home-based management of malaria strategy adapted to Sudan's conditions using artemisinin-based combination therapy and rapid diagnostic test. Malar J 2009, 8:39.

9. Mumba M, Visschedijk J, van Cleeff M, Hausman B: A Piot model to analyse case management in malaria control programmes. Trop Med Int Health 2003, 8:544-551.

10. Smith LA, Jones C, Meek S, Webster J: Provider practice and user behavior interventions to improve prompt and effective treatment of malaria: do we know what works? Am J Trop Med Hyg 2009, 80:326-335.

11. Robert V, Dieng H, Lochouran L, Traore SF, Trape JF, Simondon F, Fontenille D: [Malaria transmission in the rural zone of Niakhar, Senegal] (in French). Trop Med Int Health 1998, 3:667-677.

12. Programme National de Lutte Contre le Paludisme: Morbidité et mortalité palustre au Sénégal en 2008: Synthèse donneés districts \& hospitaux Dakar, Sénégal; 2008.

13. Ndiaye S, Ayad M: Enquête Nationale sur le Paludisme au Sénégal 2008-2009 (ENPS-II) Calverton, Maryland, USA: Centre de Recherche pour le Development Humain [Sénégal] \& Macro International Inc; 2009.

14. Programme National de Lutte Contre le Paludisme: Plan Stratégique de Lutte Contre le Paludisme au Sénégal 2006-2010 Dakar, Sénégal;; 2006.

15. UNSD: Household sample surveys in developing and transition countries New York: United Nations Statistics Division; 2005.

16. Henderson $\mathrm{RH}$, Sundaresan $\mathrm{T}$ : Cluster sampling to assess immunization coverage: a review of experience with a simplified sampling method. Bull World Health Organ 1982, 60:253-260. 
17. Lauritsen J: EpiData Data Entry, Data Management and basic Statistical Analysis System Version 3.1. Odense, Denmark: EpiData Association; 2000

18. Stata Corp LP: Stata Data Analysis \& Statistical Software Version 10. College Station, Texas; 2007.

19. Vyas S, Kumaranayake L: Constructing socio-economic status indices: how to use principal components analysis. Health Policy Plan 2006, 21:459-468.

20. RBM: Framework for monitoring progress and evaluating outcomes and impact Geneva: Roll Back Malaria Partnership; 2000.

21. Hetzel MW, Obrist B, Lengeler C, Msechu JJ, Nathan R, Dillip A, Makemba AM, Mshana C, Schulze A, Mshinda H: Obstacles to prompt and effective malaria treatment lead to low community-coverage in two rural districts of Tanzania. BMC Public Health 2008, 8:317.

22. Amin AA, Marsh V, Noor AM, Ochola SA, Snow RW: The use of formal and informal curative services in the management of paediatric fevers in four districts in Kenya. Trop Med Int Health 2003, 8:1143-1152.

23. Rutebemberwa E, Pariyo G, Peterson S, Tomson G, Kallander K: Utilization of public or private health care providers by febrile children after user fee removal in Uganda. Malar J 2009, 8:45.

24. Ndiaye S, Ayad M: Enquete Nationale sur le Paludisme au Senegal 2008-2009 (ENPS-II) Calverton, Maryland, USA: Centre de Recherche pour le Development Humain [Sénégal] \& Macro Internationl Inc; 2009.

25. Nsungwa-Sabiiti J, Tomson G, Pariyo G, Ogwal-Okeng J, Peterson S: Community effectiveness of malaria treatment in Uganda-a long way to Abuja targets. Ann Trop Paediatr 2005, 25:91-100.

26. Reyburn H, Mbakilwa H, Mwangi R, Mwerinde O, Olomi R, Drakeley C, Whitty CJ: Rapid diagnostic tests compared with malaria microscopy for guiding outpatient treatment of febrile illness in Tanzania: randomised trial. BMJ 2007, 334:403.

27. Bisoffi Z, Sirima BS, Angheben A, Lodesani C, Gobbi F, Tinto H, Van den Ende J: Rapid malaria diagnostic tests vs. clinical management of malaria in rural Burkina Faso: safety and effect on clinical decisions. A randomized trial. Trop Med Int Health 2009, 14:491-498.

28. Skarbinski J, Ouma PO, Causer LM, Kariuki SK, Barnwell JW, Alaii JA, de Oliveira AM, Zurovac D, Larson BA, Snow RW, Rowe AK, Laserson KF, Akhwale WS, Slutsker L, Hamel MJ: Effect of malaria rapid diagnostic tests on the management of uncomplicated malaria with artemetherlumefantrine in Kenya: a cluster randomized trial. Am J Trop Med Hyg 2009, 80:919-926.

29. Msellem MI, Martensson A, Rotllant G, Bhattarai A, Stromberg J, Kahigwa E, Garcia M, Petzold M, Olumese P, Ali A, Bjorkman A: Influence of rapid malaria diagnostic tests on treatment and health outcome in fever patients, Zanzibar: a crossover validation study. PLOS Med 2009, 6: e1000070.

30. Lubell $Y$, Reyburn H, Mbakilwa H, Mwangi R, Chonya S, Whitty CJ, Mills A: The impact of response to the results of diagnostic tests for malaria: cost-benefit analysis. BMJ 2008, 336:202-205.

31. Zikusooka CM, McIntyre D, Barnes KI: Should countries implementing an artemisinin-based combination malaria treatment policy also introduce rapid diagnostic tests? Malar J 2008, 7:176.

32. Kangwana BB, Njogu J, Wasunna B, Kedenge SV, Memusi DN, Goodman CA Zurovac D, Snow RW: Malaria drug shortages in Kenya: a major failure to provide access to effective treatment. Am J Trop Med Hyg 2009, 80:737-738.

33. Faye $B$, Offianan AT, Ndiaye JL, Tine RC, Toure W, Djoman K, Sylla K, Ndiaye PS, Penali L, Gaye O: Efficacy and tolerability of artesunateamodiaquine (Camoquin plus) versus artemether-lumefantrine (Coartem) against uncomplicated Plasmodium falciparum malaria: multisite trial in Senegal and Ivory Coast. Trop Med Int Health 15:608-613.

34. Onwujekwe O, Ojukwu J, Uzochukwu B, Dike N, Ikeme A, Shu E: Where do people from different socio-economic groups receive diagnosis and treatment for presumptive malaria, in south-eastern Nigeria? Ann Trop Med Parasitol 2005, 99:473-481.

35. Nsungwa-Sabiiti J, Peterson S, Pariyo G, Ogwal-Okeng J, Petzold MG Tomson G: Home-based management of fever and malaria treatment practices in Uganda. Trans R Soc Trop Med Hyg 2007, 101:1199-1207.

36. Onwujekwe O, Ojukwu J, Shu E, Uzochukwu B: Inequities in valuation of benefits, choice of drugs, and mode of payment for malaria treatment services provided by community health workers in Nigeria. Am J Trop Med Hyg 2007, 77:16-21.

37. Hildenwall H, Lindkvist J, Tumwine JK, Bergqvist Y, Pariyo G, Tomson G, Peterson S: Low validity of caretakers' reports on use of selected antimalarials and antibiotics in children with severe pneumonia at an urban hospital in Uganda. Trans R Soc Trop Med Hyg 2009, 103:95-101.

doi:10.1186/1475-2875-9-333

Cite this article as: Smith et al:: From fever to anti-malarial: the

treatment-seeking process in rural Senegal. Malaria Journal 2010 9:333.

\section{Submit your next manuscript to BioMed Central and take full advantage of:}

- Convenient online submission

- Thorough peer review

- No space constraints or color figure charges

- Immediate publication on acceptance

- Inclusion in PubMed, CAS, Scopus and Google Scholar

- Research which is freely available for redistribution

Submit your manuscript at www.biomedcentral.com/submit
C Biomed Central 